\title{
Epidermal naevi and bullous aplasia cutis congenita in a neonate
}

\author{
Julie S Fryburg, Kenneth E Greer
}

\begin{abstract}
The case of a neonate with cutaneous lesions consistent with epidermal naevi is presented. In addition to typical epidermal naevi, this baby had an unusual, bullous form of aplasia cutis congenita. Although aplasia cutis has been described as bullous and has been found in association with the epidermal naevus syndrome, both of these occurrences are rare in medical publications. This case illustrates an unusual presentation of epidermal naevi with bullous aplasia cutis congenita and raises difficult diagnostic and counselling issues.

( $($ Med Genet 1993;30:962-3)
\end{abstract}

The epidermal naevus syndrome (ENS) is a well described entity consisting of epidermal naevi in association with one or more extracutaneous abnormalities. We present the case of a neonate with classical cutaneous lesions of the ENS, as well as some unusual cutaneous manifestations. We also discuss the diagnostic and counselling dilemmas in making the diagnosis of ENS in the newborn.

\section{Case report}

The patient was the $3200 \mathrm{~g}$ product of a $38 \frac{1}{2}$ week uncomplicated pregnancy of a 27 year old G1P0 white female. The baby was noted immediately after delivery to have several cutaneous lesions, including four large $(2$ to $3 \mathrm{~cm}$ ) bullae above the posterior hairline (figs 1 and 2). Scalp defects were palpable at the base of these lesions. Just below these, at the top of the back, were two small, slightly raised, hyperpigmented circular 5 to $6 \mathrm{~mm}$ lesions. Each had an erythematous hue surrounding it and small tufts of hair in their centre. In addition, there were multiple salmon coloured, slightly raised linear and swirled lesions diffusely on the baby's right chest, abdomen, back, arm, hand, leg, and foot which did not cross the midline. Evaluation included skull $x$ rays that showed complete bone formation. The lesions on the posterior scalp and the top of the back were felt to be consistent with a bullous form of aplasia cutis congenita. The unilateral skin lesions were thought to represent epidermal naevi. The baby was otherwise well developed and non-dysmorphic with complete body symmetry and a normal neurological examination. Investigations for an infectious disease and head and renal ultrasound were normal. Analysis of fluid obtained from one of the bullous scalp lesions was consistent with an exudate. A biopsy obtained from the arm showed mild acanthosis and hyperkeratosis consistent with epidermal naevus. Biopsy of one of the lesions on the upper back showed a prominent increase in variable sized blood vessels in the superficial dermis consistent with haemangioma.

Review of the family history and examination of the parents was unremarkable for any abnormal cutaneous findings. The couple was counselled that in approximately 30 to $60 \%$ of cases with diffuse, unilateral epidermal naevi, these cutaneous lesions occur as part of the epidermal naevus syndrome.

\section{Discussion}

The term epidermal naevus syndrome (ENS) refers to the association of epidermal naevi with abnormalities in other organ systems. Extensive reviews of the ENS are available. ${ }^{1-3}$ Although the unilateral, diffuse skin lesions were quite characteristic of epidermal naevi, the lesions on the posterior scalp and top of the back were not. The diagnosis of aplasia cutis congenita in the scalp lesions in our patient was made somewhat difficult because of their uncharacteristic bullous appearance. Aplasia cutis congenita more typically presents as a solitary, hairless, well marginated skin lesion in the midline of the scalp. Rarely it can occur elsewhere as multiple lesions that may be bullous, ${ }^{4}$ as in our patient. Review of medical publications showed that in rare cases aplasia cutis congenita does occur in association with ENS. ${ }^{356}$

Another issue in this case was whether or not this child has the epidermal naevus syndrome or just epidermal naevi in association with aplasia cutis congenita. In a comprehensive review by Solomon and Esterly, ${ }^{1}$ they found that $65 \%$ of patients presenting with epidermal naevi had associated extracutaneous findings, thus classifying them as having ENS. A more recent review of unselected patients with epidermal naevi by Rogers $e t a l^{3}$ determined that $33 \%$ of their patients had one or

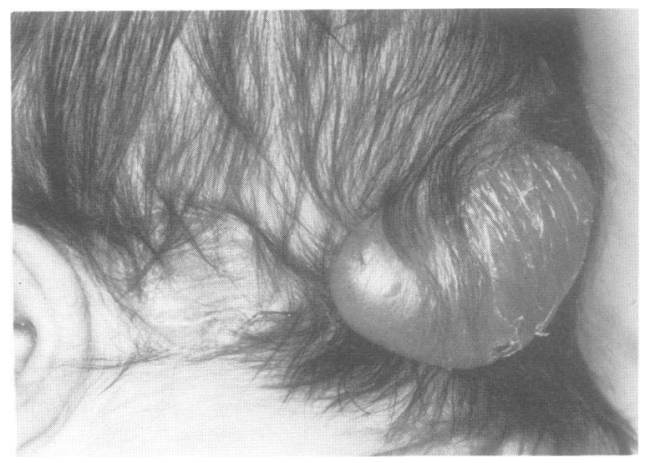

Figure 1 Occipital bullae viewed from the left. 


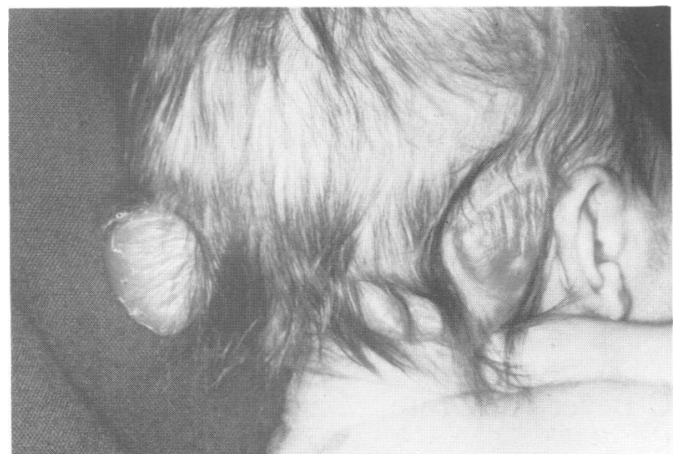

Figure 2 Occipital bullae viewed from the right.

more associated abnormalities, thus qualifying them for the diagnosis of ENS. It appears from both of these studies that extracutaneous abnormalities may occur with increased frequency in patients with more widespread naevi. ${ }^{13}$ Although our patient shows no signs of other organ involvement at present, it is unclear if his having cutis aplasia makes the likelihood of his having epidermal naevus syndrome more likely.

Most published cases show ENS to be a sporadic condition with low risks of recurrence. There are, however, rare case reports ${ }^{7}$ of families with possible autosomal dominant transmission. Since there is no family history for ENS and the parents have no sign of skin conditions, risks of recurrence for the parents of our patient would appear to be small.

It would be helpful for counselling purposes to have data from long term follow up studies of unselected patients with epidermal naevi. These might help to ascertain the most precise figures regarding incidence of the ENS in patients with epidermal naevi, as well as be useful predictors of which patients develop the syndrome and what other system involvement they might have.

1 Solomon LM, Esterly NB. Epidermal and other organoid nevi. Curr Probl Pediatr 1975;6:1-56.

2 Solomon LM, Fretzin DF, Dewald RL. The epidermal Solomon LM, Fretzin DF, Dewald RL. The epid
nevus syndrome. Arch Dermatol 1968;97:273-85.

3 Rogers M, McCrossin I, Commens C. Epidermal nevi and the epidermal nevus syndrome. $\mathcal{F}$ Am Acad Dermato 1989;20:476-88.

4 Bronspiegel N, Zelnick N, Rabinowitz H, Iancu TC. Aplasia cutis congenita and intestinal lymphangiectasia. $A m \mathcal{F} D i s$ Child 1985;139:509-13.

5 Mimouni F, Han BK, Barnes L, et al. Multiple hamartomas associated with intracranial malformations. Pediatr Dermatol 1986;3:219-25.

6 Frieden IJ. Aplasia cutis congenita: a clinical review and proposal for classification. $\mathcal{f} A m$ Acad Dermatol 1986;14:646-60.

7 Hamm H, Happle R. Inflammatory linear verrucous epidermal nevus in a mother and her daugher. Am $\mathcal{F}$ Med Genet 1986;24:685-90. 